ISSN 2306-1561

Automation and Control in Technical Systems (ACTS)

2014, No 1.2(9), pp. 70-76.

DOI: $10.12731 / 2306-1561-2014-1-20$

\title{
Control and monitoring of steam and hot water boilers in industrial plants for production of sulfur in the Republic of Iraq
}

\section{Nikolaev Andrey Borisovich}

Russian Federation, Honoris Causa, Doctor of Technical Sciences, Professor, Dean of the Faculty «Control Systems».

State Technical University - MADI, 125319, Russian Federation, Moscow, Leningradsky prospekt, 64. Tel.: +7 (499) 151-64-12. http://www.madi.ru

\section{nikolaev.madi@mail.ru}

\section{Karim Dhiya Ali H.}

Republic of Irak, Postgraduate Student, Department of «Automated Control Systems».

State Technical University - MADI, 125319, Russian Federation, Moscow, Leningradsky prospekt, 64. Tel.: +7 (499) 151-64-12. http://www.madi.ru

\section{dhiya_ali@yahoo.com}

\begin{abstract}
In boiler plants in the automatic set contains all the equipment required to ensure safe operation of the boiler with the observance of high economic and environmental indicators. Set of instrumentation and automation includes: control panel boilers, which contains the elements and devices of automatics of safety, automatic adjustment of the basic technological parameters. Automatics of safety is implemented on the basis of the relay circuit, which contains the logging devices water level in the boiler drum, pressure steam, the steam flow rate, actuating mechanisms control. The shield provides the installation of sensors control the burner flame and ignition.
\end{abstract}

Keywords: boiler, control system, hot water, steam, sulfur production. 
ISSN 2306-1561

Автоматизация и управление в технических системах (АУТС) 2014. - №1.2(9). - C. 70-76.

DOI: $10.12731 / 2306-1561-2014-1-20$

УДК 681.51.01

\section{Контроль и мониторинг бойлера в промышленной установке при производстве серы в Республике Ирак}

\section{Николаев Андрей Борисович}

Российская Федерация, Лауреат премии правительства РФ, Заслуженный деятель науки РФ, доктор технических наук, профессор, декан факультета «Управление».

ФГБОУ ВПО «Московский автомобильно-дорожный государственный технический университет (МАДИ)», 125319, Российская Федерация, г. Москва, Ленинградский проспект, д.64, Тел.: +7 (499) 151-64-12, http://www.madi.ru

\section{nikolaev.madi@mail.ru}

\section{Карим Дия Али Х.}

Республика Ирак, аспирант кафедры «Автоматизированные системы управления».

ФГБОУ ВПО «Московский автомобильно-дорожный государственный технический университет (МАДИ)», 125319, Российская Федерация, г. Москва, Ленинградский проспект, д.64, Тел.: +7 (499) 151-64-12, http://www.madi.ru

Аннотация. В котельных установках в комплект автоматики входит оборудование, необходимое для обеспечения безопасной работы котла с соблюдением высоких экономических и экологических показателей. Комплект контрольно-измерительных приборов и автоматики (КИПиА) включает в себя: щит управления котла, в котором находятся элементы и приборы автоматики безопасности, автоматика регулирования основных технологических параметров. Автоматика безопасности выполнена на базе релейной схемы, в которой находятся приборы регистрации уровня воды в барабане котла, давления пара, расхода пара, управления исполнительными механизмами. В щите предусмотрена установка сигнализаторов контроля пламени горелки и запальника.

Ключевые слова: бойлер, контроль, горячая вода, пар, производство серы. 


\section{1. Введение}

Надежность и безопасность котельных, как и продолжительность их работы, закладываются не только особенностями конструкций, их составляющих, наличием систем безопасности, соблюдением регламентированных строительных норм и квалифицированно выполненным монтажом. Обслуживание котельных подразумевает комплекс мероприятий по контролю и отладке сложного оборудования, работающего на стыке множества наук: термодинамики, газовой динамики, гидравлики, химической очистки воды, теории горения и др. Качественный сервис подразумевает взаимосвязь всех упомянутых процессов, понимание взаимодействия всех элементов, составляющих единое целое котельной. Именно поэтому весьма существенным фактором безаварийной эксплуатации является обеспечение грамотного обслуживания каждого функционального узла высококвалифицированным персоналом.

\section{2. Паровой котел}

Паровой котел представляет собой закрытый сосуд, предназначенный для преобразования воды в пар. Это преобразование происходит внутри котла при определенных давлении и температуре. В зависимости от давления пара котлы делятся на категории:

1) Котлы низкого давления (Steam < 100 psi).

2) Котлы среднего давления (100 psi <= Steam > 600 psi).

3) Котлы высокого давления (Steam >= 600 psi).

Котлы, используемые при производстве серы, являются котлами высокого давления.

Есть три этапа преобразования бессолевой воды в перегретый водяной пар (рисунок 1): нагревание воды, превращение воды в пар и преобразование насыщенного пара в перегретый пар.

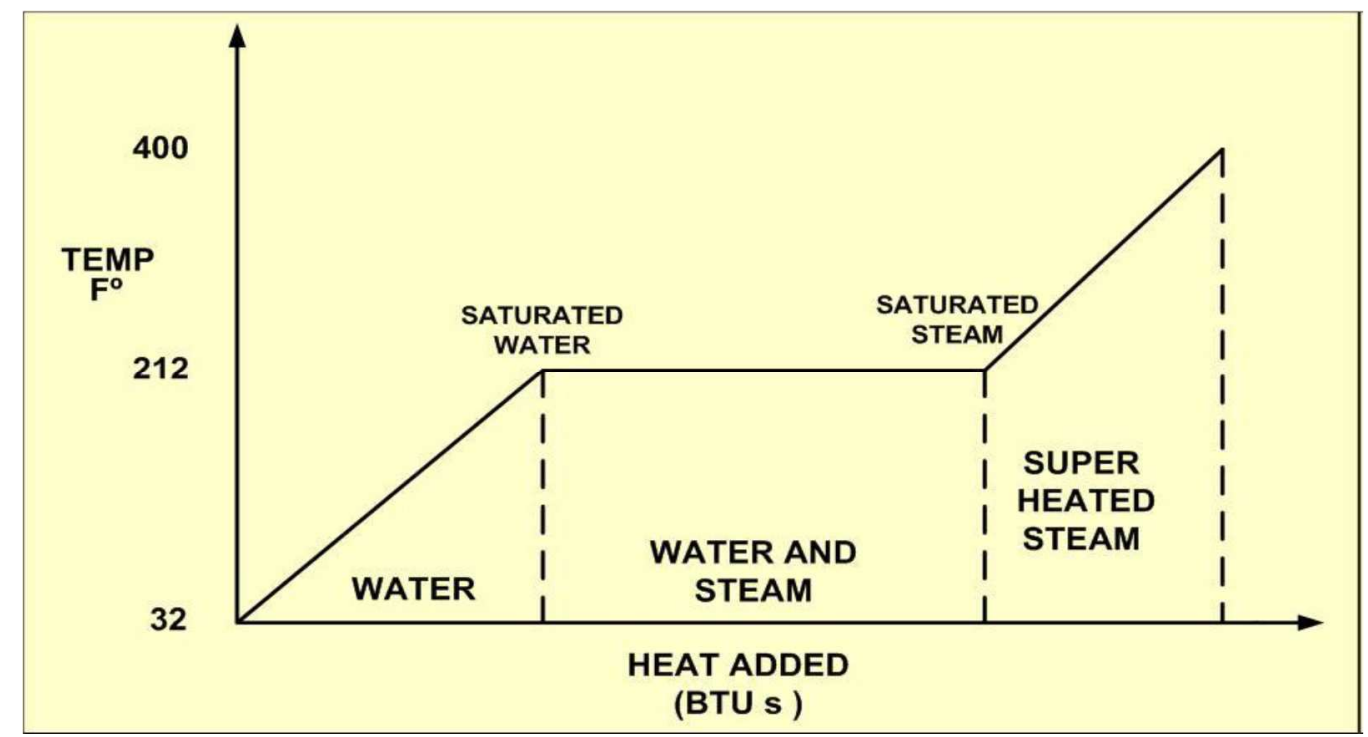

Рисунок 1 - Этапы превращения воды в пар 
Данные о состоянии производства и аварийные сигналы применяются при оперативном управлении и частично накапливаются для статистических расчетов и анализа [1 - 14]. Значительная часть этих данных может собираться в виде отклонений от плана, нормы, задания. Данные оперативного учета используются также при оперативном планировании. Основным путем повышения качества управления является автоматизация управления производством, при которой перечисленные задачи решаются средствами вычислительной техники.

Сложность управления технологическим процессом определяется суммарными потоками информации, которые выявляются в процессе тщательного изучения и анализа, сложностью их обработки и использования результатов. Эти потоки определяют число датчиков, устанавливаемых в АСУ ТП [1, 2, 11 - 14]:

1) Контроль Уровня: Датчик измерения уровня.

2) Контроль давления: Датчик измерения давления.

3) Управление потоком: Воздушный поток, Поток пара, расход воды

4) Контроль температуры: Датчик регулирования потока.

Таблица 1 - Типовой набор параметров опрашиваемого сигнала

\begin{tabular}{|l|c|c|c|c|}
\hline & Датчик уровня & $\begin{array}{c}\text { Датчик } \\
\text { Давления }\end{array}$ & $\begin{array}{c}\text { Датчик } \\
\text { Температуры }\end{array}$ & $\begin{array}{c}\text { Датчик } \\
\text { потока }\end{array}$ \\
\hline Бойлер & - & $\sqrt{ }$ & $\sqrt{ }$ & - \\
\hline Пар & $\sqrt{ }$ & $\sqrt{ }$ & $\sqrt{ }$ & $\sqrt{ }$ \\
\hline Вода & $\sqrt{ }$ & $\sqrt{ }$ & - & $\sqrt{ }$ \\
\hline Газ & $\sqrt{ }$ & $\sqrt{ }$ & - & \\
\hline Воздух & $\sqrt{ }$ & $\sqrt{ }$ & \\
\hline $\begin{array}{l}\text { Газовый } \\
\text { резервуар }\end{array}$ & & & & \\
\hline $\begin{array}{l}\text { Воздушный } \\
\text { резервуар }\end{array}$ & & & & \\
\hline
\end{tabular}

\section{3. Алгоритм автоматизированного} установленных в дополнительном бойлере

Основной функцией программируемого логического контроллера (ПЛК) является постоянное сканирование программы [2 - 5]. Процесс сканирования состоит из трех основных этапов.

Этап 1: тестирование состояние входных данных. На первом этапе ПЛК проверяет каждый из входных данных и определяет статус подключения. Говоря иначе, ПЛК проверяет, является ли датчик или коммутатор включенным или нет. Таким образом, на этом этапе информация сохраняется в памяти, для того чтобы она могла быть использована на следующих этапах.

Этап 2: выполнение программы. На этом этапе контролер выполняет команды программы в соответствии с инструкцией, основанной на информации, полученной на предыдущей стадии, и принимаются соответствующие действия. На данном этапе 
происходит активация определенных выходов и результаты могут быть откладываться и сохраняются в памяти, чтобы получить их позднее на следующих этапах.

Этап 3: проверка и корректировка состояния выходных данных. На заключительном этапе контроллер проверяет и корректирует выходные сигналы. Корректировка выполняется в зависимости от состояния входных данных, которые были получены на первом этапе, а также на основании результатов полученных на втором этапе. После выполнения действий на третьем этапе ПЛК возвращается в начало цикла и действия повторяются.

Длительность цикла сканирования определяется суммой длительностей выполнения всех трех этапов.

Дополнительный бойлер установлен на производственном объекте и служит для поддержания технологически необходимой температуры воды, поступающей с объекта-2 (рисунок 2).

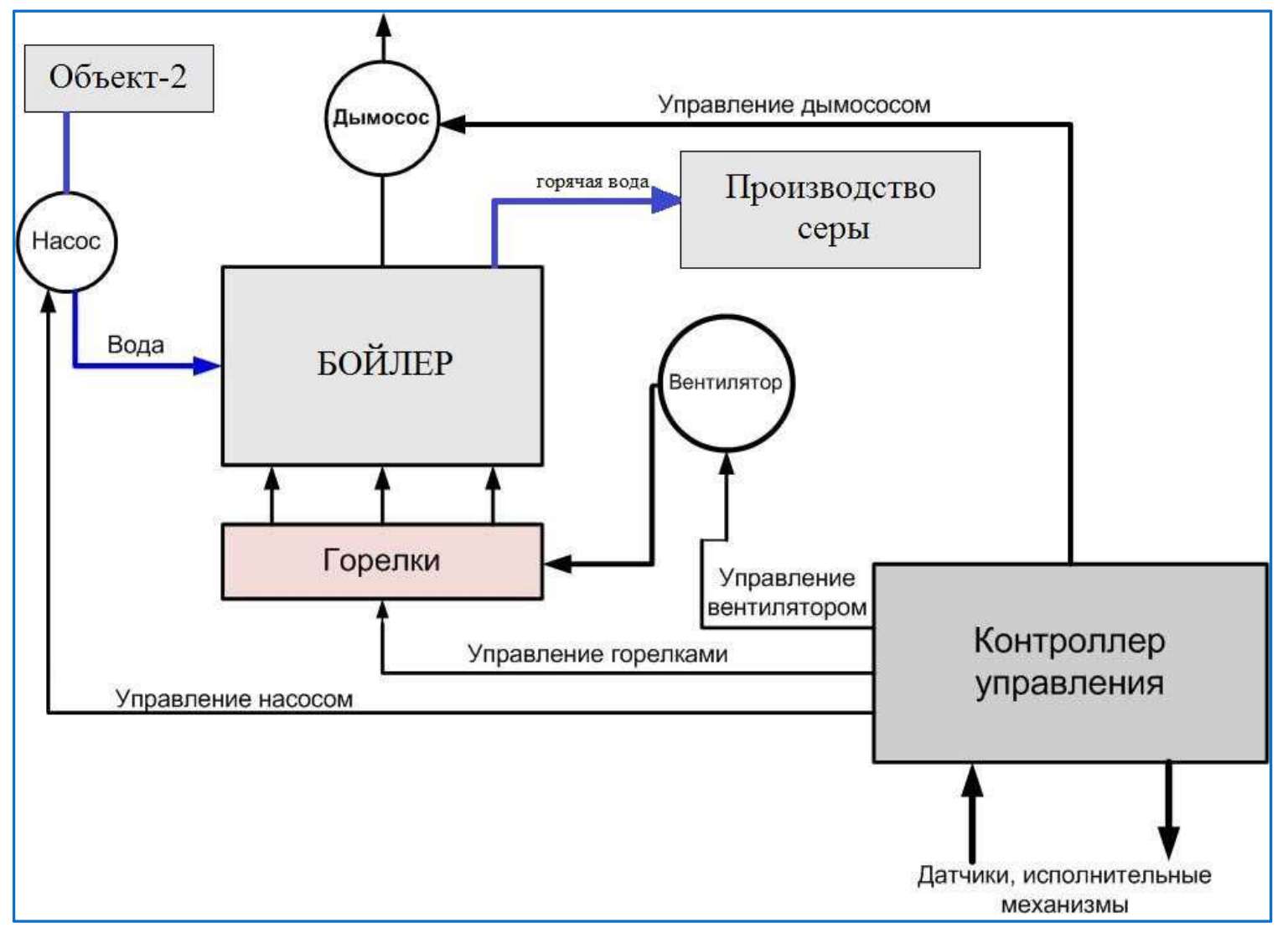

Рисунок 2 - Схема АСУ дополнительного бойлера

Элементами контроля и управления АСУ дополнительного бойлера являются:

- система розжига горелок бойлера;

- система управления процессом производства горячей воды требуемого количества и качества;

- $\quad$ система регулирования уровня воды в барабане.

Алгоритм контроля измерителей (датчиков) дополнительного бойлера представлен на рисунке 3. 


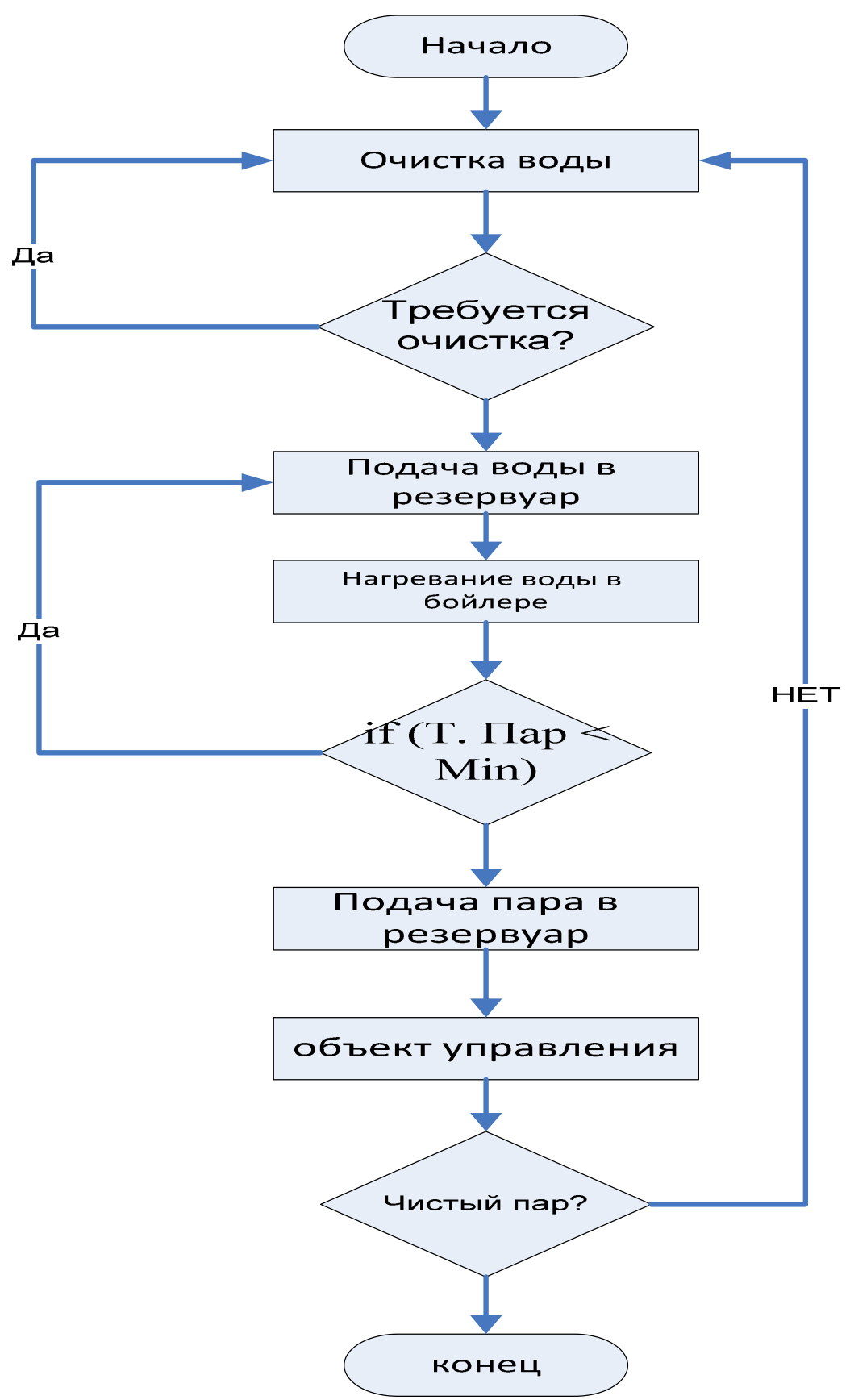

Рисунок 3 - Схема алгоритма контроля измерителей (датчиков) дополнительного бойлера

\section{4. Заключение}

Полученные результаты позволяют сделать вывод о том, что за счет автоматизации процессов контроля температуры и давления возможно существенно повысить основные характеристики производственного процесса. Предложенный алгоритм контроля датчиков обеспечивает обработку больших объемов информации в реальном масштабе времени и позволяет повысить скорость и надежность принятия решений в случае возникновения аварийных ситуаций. При этом существует возможность сокращения обслуживающего персонала. 


\section{Список информационных источников}

[1] Марсов В.И. Принципиальные электрические схемы экстремальной системы регулирования процессом транспортирования нефти / А.В. Илюхин, В.И. Марсов, А.Б. Николаев, А.В. Остроух // Промышленные АСУ и контроллеры. - М.: «Научтехлитиздат», 2013. - №1. - С. 50-61.

[2] Остроух А.В. Основы построения систем искусственного интеллекта для промышленных и строительных предприятий: монография / А.В. Остроух. - М.: OОО «Техполиграфцентр», 2008. - 280 с. - ISBN 978-5-94385-033-2.

[3] Остроух А.В. Информационные технологии в научной и производственной деятельности / [ред. А.В. Остроух] - М: ООО "Техполиграфцентр", 2011. - 240 с. ISBN 978-5-94385-056-1.

[4] Остроух А.В. Ввод и обработка цифровой информации: учебник для нач. проф. образования / А.В. Остроух. - М.: Издательский центр «Академия», 2012. - 288 с. - ISBN 978-5-7695-9457-1.

[5] Остроух А.В. Системы искусственного интеллекта в промышленности, робототехнике и транспортном комплексе: монография / A.В. Остроух Красноярск: Научно-инновационный центр, 2013. - 326 с. - ISBN 978-5-906314$10-9$.

[6] Остроух А.В., Тянь Юань. Современные методы и подходы к построению систем управления производственно-технологической деятельностью промышленных предприятий // Автоматизация и управление в технических системах. - 2013. - № 1(3). - C. 29-31.

[7] Остроух А.В., Тянь Юань Разработка системы мониторинга производственнотехнологической деятельности промышленных предприятий Китая // Автоматизация и управление в технических системах. - 2013. - № 2(4). - С. 73-76.

[8] Остроух А.В. Интеграция компонентов системы мониторинга / А.В. Остроух, Юань Тянь // Молодой ученый. - Чита: ООО «Издательство Молодой ученый», 2013. - №10. - С. 182-185.

[9] Остроух А.В., Николаев А.Б., Сальный А.Г., Кухаренко В.Н. Общие принципы построения SCADA-систем // Автоматизация и управление в технических системах. - 2013. - № 2(4). - С. 8-12.

[10] Nickolayev A.B., Ostroukh A.V., Zamytskikh P.V., Gubanov A.I. Automated system of oil quantity and quality indexes estimation // EUROPEAN JOURNAL OF NATURAL HISTORY. - 2011. - № 3 - C. 96-98.

[11] K. Gowri Shankar, Control of Boiler Operation using PLC - SCADA, Proceedings of the International MultiConference of Engineers and Computer Scientists 2008 Vol II, IMECS 2008, 19-21 March, 2008, Hong Kong

[12] Boyer, Stuart, A. SCADA: Supervisory Control and Data Acquisition, Instrument Society of America, Research Triangle, NC. 1993.

[13] Ezell, Barry, "Supervisory Control and Data Acquisition Systems for Water Supply and Its Vulnerability to Cyber Risks" available on the internet at: http://watt.seas.virginia.edu/ bce4k/home.html. (August 1997).

[14] K. Gowri Shankar," His areas of interest in process control are nonlinear control, PID Control and Automation", lecturer of the Department of Electronics \& Communication Engineering, Rajiv Gandhi College of Engineering \& Technology, Pondicherry, India. 